\title{
Experimental determination of the local heat transfer coefficient on a thermally thick wall downstream of a backward-facing step
}

\author{
F. Boizumault, S. Harmand, B. Desmet
}

LAMIH-Conception des Systèmes Mécaniques et Energétiques, UVHC, BP 311, 59304 Valenciennes Cedex

\section{Abstract}

A heat transfer measurement technique based on the combination of infrared thermography and numerical computation is presented in the case of a turbulent reattachment downstream of a backwardfacing step. The presence of a $\mathrm{CaF}_{2}$ window and low surface temperatures has led to develop a specific infrared system calibration. Heat transfer measurement technique and infrared system calibration are both presented in this paper.

\section{Introduction}

Aerodynamic perturbations in separated flows can cause large variations of the local heat transfer coefficient. This phenomenon affects many industrial applications (electronic circuitry, combustion chambers, heat transfer devices...). So, it is the subject of many works but the scope of the problem is still a topical issue $[1,2,3]$. The experimental determination of the heat transfer coefficient variations assumes that temperature gradients on the observed wall are sufficiently large. Most of the recent works on heat transfer in separated flows were carried out by means of the "heated-thin-foil" technique (conduction free), and infrared thermography measurement of wall temperature seems to prevail over thermocouples $[4,5,6]$. Combination of infrared thermography and "heated-thin-foil" technique offers great possibilities and gives the required results for such studies. However, because of the difficulty to fix thin foil for complex geometries, this paper suggests to determine heat transfer coefficient maps on thick walls of low thermal conductivity. Then, temperature gradients generated by the heat transfer coefficient variations depend on the wall thermal conductivity. The heat flux exchanged with the separated flow is obtained from the combination of infrared thermography measurements and computational code.

\section{Procedure and experimental apparatus}

The heat flux distribution is determined from the experimental measurements of temperature by solving the steady state heat equation in the thick wall. The local heat transfer coefficient is calculated by making an energy balance on the surface exposed to the flow.

The heat transfer measurement technique is presented in the case of a backward-facing step configuration. The expansion ratio is 1.5 and the aspect ratio is 18.75 (bidimensional flow). The boundary layer at the separation is laminar for all experiments. The range of the Reynolds number based on the hydraulic diameter of the inlet section is 6000 to 21000 . According to Adams and Johnston, [7], this Reynolds number range always leads to turbulent reattachment.

A low thermal conductivity heat transier measurement plate (made of perspex) is placed behind the step. One side is maintained at a constant temperature (approximately $60^{\circ} \mathrm{C}$, measured by thermocouples) by application on an aluminium support and the other one is exposed to the separated flow. The temperature of this face (black paint coated) is measured by infrared thermography through a $\mathrm{CaF}_{2}$ window. The heat flux is computed from a finite element model of the measurement plate using the measured temperatures as boundary conditions (figure 1). Boundary conditions of lateral sides of the computing domain are not determined. Several boundary conditions types have been tested and the adiabatic condition has been chosen. The computation code gives the heat flux at each node i,j of the face exposed to the flow and the local heat transfer coefficient $h$ is given by :

$$
\varphi_{i, j}=h \cdot\left(T_{i, j}-T_{\infty}\right)+\sigma \cdot \varepsilon \cdot\left(T_{i, j}^{4}-T_{r e f}^{4}\right)
$$

where $T_{\infty}$ is the temperature of the flow measured by thermocouple at the entrance region, $\sigma$ is the Stefan-Boltzmann constant and $\varepsilon$ is the heat transfer test plate emissivity. The large size of 
the plate in front of the measurement region allows to neglect the view factor effect, and its temperature is approximately equal to the atmospheric temperature, so $\mathrm{T}_{\text {ref }}$ is taken equal to the atmospherictemperature.

In practice, each node of the heat transfer measurement plate mesh is associated with a pixel of the infrared image. The large number of discretization points allows to fit evolutions even in zones of important gradient, but imposes a numerical treatment of the data. The infrared system, the calibration computer, and the computational code computer are connected in a network. The infrared system is the AGEMA 900 SWTE (operating waveband : 2 - $5.4 \mu \mathrm{m}$ ). SPRITE detectors are cooled by Peltier effect, so the infrared system can operate continuously (steady state measurements). Measurements are averaged on 32 images, then the NETD (Noise Equivalent Temperature Difference) is about $0.02^{\circ} \mathrm{C}$ at $30^{\circ} \mathrm{C}$. The SRF (Slit Response Function) gives a $2 \%$ attenuation for a 12.5 mrad width slit.

\section{Temperature measurements and infrared system calibration}

The radiation measurement situation is shown in figure 2. The $\mathrm{CaF}_{2}$ window is placed at about $50 \mathrm{~cm}$ from the infrared camera ; reflection and emission effects on the window are observed. The most significant is the Narcissus effect : the infrared system detects the reflection of the camera itself (figure 3). As the use of low thermal conductivity material generates low surface temperatures (the measured temperatures range from 30 to $60^{\circ} \mathrm{C}$ ) these effects are significant. These perturbations are not uniform on the window surface and do not allow direct map measurements. So, measurements are made by substracting a reference image from the thermal image.

The radiation equation is : (written for the radiation signal)

$$
\begin{array}{ll}
S_{\mathrm{r}}(T)=\tau_{\mathrm{atm}} \cdot S_{\text {win }}(T)+\left(1-\tau_{\mathrm{atm}}\right) \cdot S\left(\mathrm{~T}_{\mathrm{atm}}\right) & \text { received by the camera } \\
S_{\text {win }}(T)=\tau_{\text {win }} \cdot S_{\mathrm{ts}}(T)+\rho_{\text {win }} \cdot S\left(\mathrm{~T}_{\mathrm{e}}\right)+\varepsilon_{\text {win }} \cdot S\left(\mathrm{~T}_{\text {win }}\right) & \text { from the window } \\
S_{\mathrm{ts}}(\mathrm{T})=\varepsilon \cdot S(T)+(1-\varepsilon) \cdot S\left(\mathrm{~T}_{\mathrm{amb}}\right) & \text { from the test section }
\end{array}
$$

where $\mathrm{S}(\mathrm{T})$ is the digitized black body radiation signal at temperature $\mathrm{T}$.

The reference image is taken when the heat transfer test plate is at atmospheric temperature. The radiation equation becomes:

$$
\begin{aligned}
& S_{r}\left(T_{a t m}\right)=\tau_{a t m} \cdot S_{\text {win }}\left(T_{a t m}\right)+\left(1-\tau_{a t m}\right) \cdot S\left(T_{a t m}\right) \\
& S_{\text {win }}\left(T_{a t m}\right)=\tau_{\text {win }} \cdot S_{t s}\left(T_{a t m}\right)+\rho_{\text {win }} \cdot S\left(T_{e}\right)+\varepsilon_{w i n} \cdot S\left(T_{w i n}\right) \\
& S_{t s}\left(T_{a t m}\right)=\varepsilon \cdot S\left(T_{a t m}\right)+(1-\varepsilon) \cdot S\left(T_{a m b}\right)
\end{aligned}
$$

By substracting the reference image from the measurement image one obtains :

$$
\mathrm{S}_{\mathrm{r}}(\mathrm{T})-\mathrm{S}_{\mathrm{r}}\left(\mathrm{T}_{\mathrm{atm}}\right)=\tau_{\mathrm{atm}} \cdot \tau_{\mathrm{win}} \cdot\left(\varepsilon \cdot \mathrm{S}(\mathrm{T})-\varepsilon \cdot \mathrm{S}\left(\mathrm{T}_{\mathrm{atm}}\right)\right)
$$

Then, calibration consists in associating a value of temperature $T$, measured on the measurement plate surface by a thin thermocouple, to $V(T)=\tau_{\text {atm }} \tau_{\text {win }} \varepsilon S(T)$. The radiation equation after substraction is :

$$
V(T)=S_{r}(T)-S_{r}\left(T_{a t m}\right)+V\left(T_{a t m}\right)
$$

So, the temperature map measurement is carried out by substracting the raw and reference images and compensating with a uniform distribution (atmospheric temperature calibration data). The effect of the correction by substracting images is shown in figure 4. Correction equivalent temperature difference is about $0.5^{\circ} \mathrm{C}$ and can reach $1^{\circ} \mathrm{C}$ at higher atmospheric temperatures. Substraction corrects the general temperature profile shape and can displace the location of the maximum heat transfer point. 
In practice, calibration was made in the measurement situation without a window, and $\tau_{\text {win }}$ was evaluated separately by measuring a high black body radiation signal through the window. Validation measurement points of the calibration are shown in figure 5.

\section{Results and discussion}

Local heat transfer coefficient is shown in a non-dimensional form by means of the Nusselt number (based on the hydraulic diameter at the entrance section $=\mathrm{Dh}$ ) :

$$
\mathrm{Nu}=\frac{h \mathrm{Dh}}{\lambda_{\mathrm{f}}}
$$

where the fluid thermal conductivity is evaluated at the film temperature. The measurements are performed on the centerline of the channel.

Figure 6 compares several lateral sides boundary conditions that have been tested for the finite element computation. Differences between these cases are only significant in the region close to the step because of the virtual variation of the measured temperature (spatial resolution of the infrared detector). However, these differences are observed only on four or five nodes from the step (figure 6(a)). Far away from the step, surface temperature variations are low, so both the adiabatic condition and the linear temperature condition are nearly equivalent (one dimensional diffusion problem) and realistic (figure $6(\mathrm{~b})$ ). Results are displayed within the region ranging from 1 to $15.5 \mathrm{H}(\mathrm{H}=$ step height $=4 \mathrm{~mm})$.

The recirculation length $X_{r}$ principally depends on the step height and on the Reynolds number at the step section (also, the Reynolds number is based on the hydraulic diameter of the entrance section). For a laminar reattachment $X_{r}$ increases with Reynolds number and decreases during transition to reach a constant value (depending on the step height) for the fully turbulent reattachment. In the present case $X_{r}$ is about $6 \mathrm{H}$. The general thermal behaviour of the heat transfer downstream of a backward-facing step is well known. Heat transfer is low in the recirculation region, maximum in the shear layer reattachment region and then decreases in the redevelopment region as a boundary layer (figure 7 ).

For several Reynolds number, figure 8 shows the agreement of the longitudinal Nusselt profiles with the fully developed Nusselt number according to [8]. The maximum heat transfer occurs at $X_{\max }$, near $X_{r}$ (generally $\left.X_{\max }<X_{r},[9,6]\right)$. Reattachment seems to be fully turbulent for $\mathrm{Re} \approx 10000\left(X_{\max } \approx 6 \mathrm{H}\right)$, it is transitional before this value. The maximum Nusselt number, Numax, increases with the Reynolds number and this dependence has been correlated in figure 9 . The power of the Reynolds number is 0.64 , close to the common value $2 / 3$ in the literature, $[10,11,12,6]$.

\section{Conclusion}

Local heat transfer measurements downstream of a backward-facing step are performed on a thick plate by means of the combination of infrared thermography and of a computation code. The experimental technique has led to develop a specific infrared system calibration, based on images substraction. This calibration gives the expected results and the heat transfer measurements are in agreement with literature. Heat flux computation does not require that the boundary conditions of the lateral sides of the model have to be determined (result is influenced on few nodes only). Finally, network processing allows to compute the local heat transfer with the best resolution (one node per pixel).

The proposed method proves to be efficient in some situations when the "heated-thin-foil" technique is not usable. 


\section{REFERENCES}

[1] KIM (K.C.) and LEE(Y.) - Effect of transverse convex curvature on heat transfer from heated cylinders with axisymmetric bacward-facing steps. Int. J. Heal Mass Transfer, Vol. 39, N8, 1996, p 1763-1767.

[2] MOTTAHED (B.) AND MOLKI (M.) - Artificial roughness effects on turbulent transfer coefficient in the entrance region of a circular tube. Int. J. Heat Mass Transfer, Vol. 39, №12, 1996, p 2515-2523.

[3] YANG (J.T.) and TSAI (C.H.) - High temperature heat transfer of separated flow over a suddenexpansion with base mass injection. Int. J. Heat Mass Transfer, Vol. 39, 1986, p 2293-2301.

[4] SCHERER (V.), WITTIG (S.), and PFEIFFER (A.) - Thermographic heat transfer measurements in separated flows. Experiments in fluids, Vol. 14, 1993, p 17-24.

[5] CARDONE (G.), di LEVA (O. M.) and CARLOMAGNO (G.) - Heat transfer measurements and surface flow visualization of a backward-facing step turbulent flow. Exp. and Num. Flow Visualization, Vol. 172, 1993, p 35-42.

[6] DUMOULIN (J.) - Méthodes de détermination, par thermographie infrarouge, des coefficients d'échange de chaleur moyens et instationnaires en aérodynamique perturbée. PhD thesis, INSA Toulouse, $n^{\circ} 276,1994$. [in french]

[7] ADAMS (E. D.) and JOHNSTON (J. P.) - Effects of the separating shear layer on the reattachment flow structure. Part 2 : Reattachment length and wall shear stress. Experiments in fluids, vol. 6, 1988, p 493 499.

[8] SPARROW (E.M.) and CUR (N.) - Tubulent heat transfer in a symmetrically or asymetrically heated flat rectangular duct with flow separation at inlet. Journal of Heat Transfer, Vol. 104, 1982, p 82-89.

[9] SPARROW (E.M), KANG (S.S.) AND CHUCK (W.) - Relation between the points of flow reattachment and heat transfer for regions of flow separation. Int. J. Heat Mass Transfer, Vol. 30, 1987, p 1237-1246.

[10] KRALL (K.M.) and SPARROW (E.M.) - Turbulent heat transfer in the separated, reattached, and redeveloppment regions of a circular tube. Journal of Heat Transfer, Vol. 88, 1966, p 131-136.

[11] ZEMANICK (P.P.) and DOUGALL (R.S.) - Local heat transfer downstream of abrupt circular channel expansion. Journal of Heat Transfer, Vol. 92, 1970, p 53-60.

[12] GARCIA (A.) and SPARROW (E.M.) - Turbulent heat transfer downstream of a contraction-related, forward facing-step in a duct. Journal of Heat Transfer, Vol. 109, 1987, p 621-626.

\section{FIGURES}
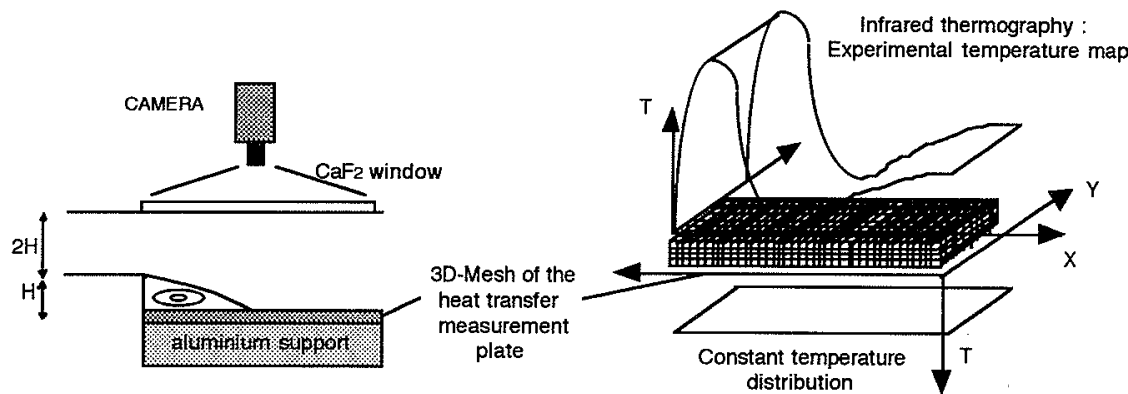

Fig. 1. - Heat transfer measurement plate and boundary conditions 


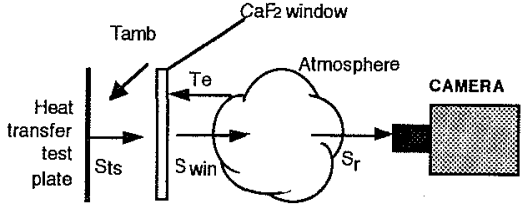

Fig. 2. - Measurement situation

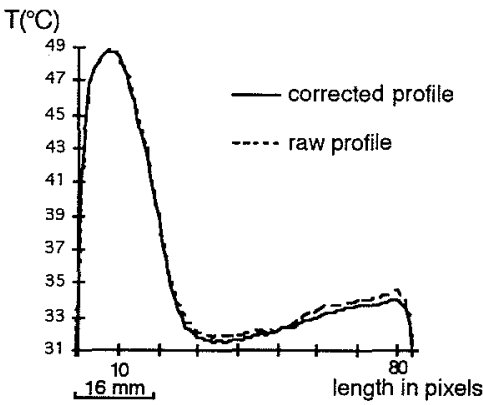

Fig. 4. - Correction effect example

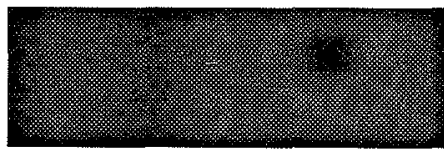

Fig. 3. - Narcissus effect example

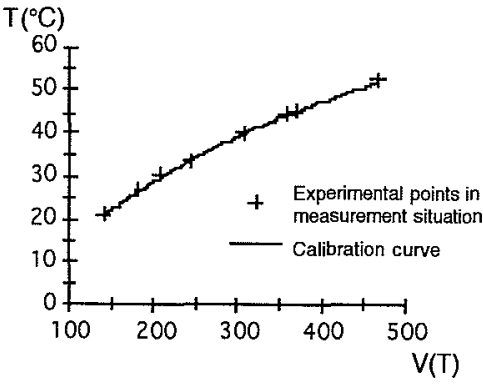

Fig. 5. - Calibration validation

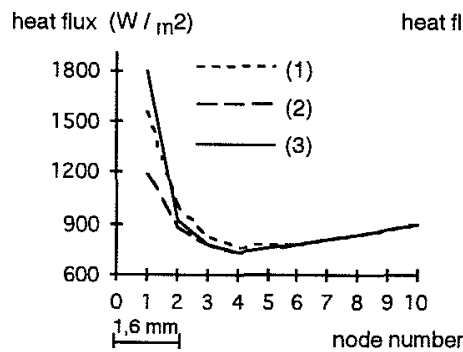

(a)

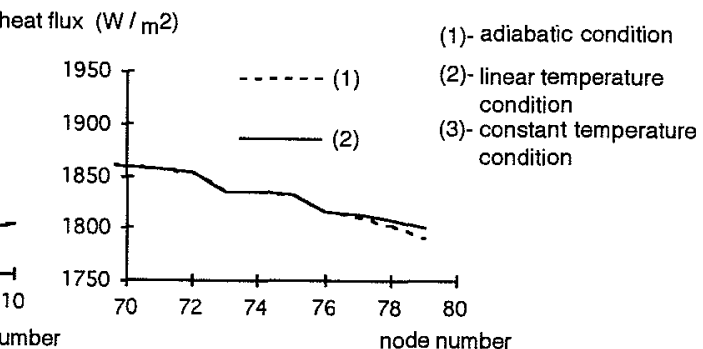

(b)

Fig. 6. - Boundary condition type influence

(a) : step edge

(b) : redevelopment edge 


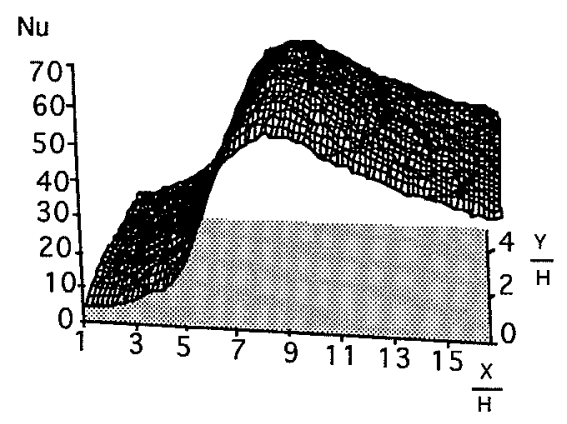

Fig. 7. - Nusselt number cartography

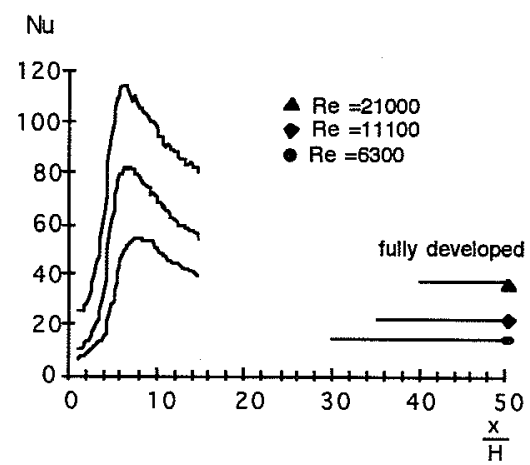

Fig. 8. - Nusselt number profiles

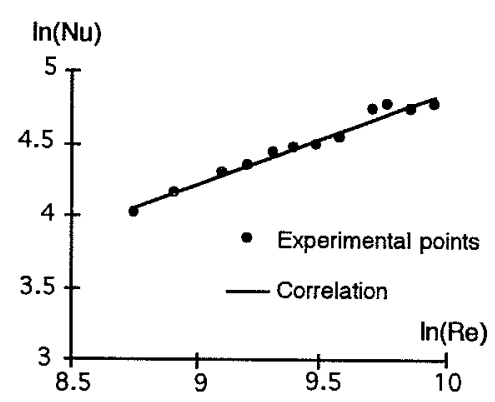

Figure $9-\mathrm{Nu}=0.205 \mathrm{Re}^{0.64}$ 